\title{
Effect of Racemic Epinephrine on Ventilatory Function in the Neonate Postextubation
}

\author{
SHERRY E. COURTNEY, JOHN P. WACHTL, JOHN F. HOPSON, AND R. M. SIERVOGEL \\ Department of Pediatrics, Divisions of Neonatalogy and Human Biology, Wright State University School of \\ Medicine; and the Children's Medical Center, Dayton, Ohio 45404
}

\begin{abstract}
The use of nebulized racemic epinephrine to improve ventilatory function in the newborn postextubation was studied. Forty-five infants intubated for more than 3 days were randomized to receive racemic epinephrine by nebulization immediately postextubation or to receive only warmed, humidified gas. Measurements of air flow, esophageal pressure, tidal volume, respiratory rate, and heart rate were made before treatment and every $10 \mathrm{~min}$ for $1 \mathrm{~h}$ after treatment. Resistance was calculated from recorded data. Changes from baseline values were calculated for each time period. Analysis of variance of these variables for treatment, sex, and time main effects and their interactions, with appropriate adjustments for covariables, was performed. Although some sex interactions were seen, there were no significant time effects or interactions. This study provides no evidence that using nebulized racemic epinephrine in infants postextubation improves ventilatory function. (Pediatr Res 21: 381-385, 1987)
\end{abstract}

\section{Abbreviations}

Pes, esophageal pressure

$V_{t}$, tidal volume

HR, heart rate

$R R$, respiratory rate

$\dot{V}$, flow rate

$\mathbf{R}_{\mathrm{L}}$, total pulmonary resistance

ANOVA, analysis of variance

CPAP, continuous positive airway pressure

SAS, statistical analysis system

Nebulized racemic epinephrine has been routinely used in our nursery and elsewhere to prevent postextubation respiratory distress due to stridor. Although no controlled studies have evaluated the effectiveness of this therapy, at least one serious complication, paroxysmal supraventricular tachycardia, has been reported (1). A recent nonrandomized report of 10 infants indicated increases in inspiratory flow rates and tidal volume and decreases in respiratory rate with no change in minute ventilation following racemic epinephrine treatment (2). Despite the paucity of data, major textbooks suggest this therapy to relieve laryngeal edema $(3,4)$. The present prospective study was therefore designed to evaluate the efficacy of routine use of racemic epinephrine aerosol postextubation in the neonate.

\section{MATERIALS AND METHODS}

Forty-five infants were included in the study. After parental informed consent was obtained, babies were randomized into

Received February 24, 1986; accepted November 25, 1986

Address for correspondence and reprints to Sherry E. Courtney, M.D., Department of Newborn Medicine, Children's Medical Center, One Children's Plaza, Dayton, OH 45404 two groups. The treatment group received nebulized racemic epinephrine by face mask following extubation; the control group received only warm, humidified gas. All infants had been intubated for a minimum of 3 days [mean $12.2 \pm 16.1$ days (SD)]. The reasons for intubation were respiratory distress syndrome in 38 babies, transient tachypnea in three, persistent fetal circulation in three, and severe asphyxia in one. As gestational age has been shown not to be a factor in predictions of laryngeal injury, no attempt was made to separate preterm from term infants (5). Any infant who had previously received racemic epinephrine or any infant who had received steroids to decrease tracheal edema was excluded from the study. The study was initiated at the time of extubation. All infants had been weaned to $2-3 \mathrm{~cm} \mathrm{H}_{2} \mathrm{O}$ CPAP and had maintained satisfactory blood gases for a minimum of $1 \mathrm{~h}$ prior to extubation. Infants were studied under radiant warmers and skin temperature was maintained by servo-control at $36.5^{\circ} \mathrm{C}$. Blood gases were obtained on all infants just prior to and immediately following the study period.

Extubation technique. The need for tracheal suction prior to extubation was based on auscultation of breath sounds and was determined approximately $30 \mathrm{~min}$ prior to extubation. All infants were given three to five manual positive pressure breaths using a Mapleson valve/anesthesia bag setup with an in-line manometer. Oxygen was given as required. $\mathrm{FiO}_{2}$ utilized was identical to that which the patient was receiving on CPAP, and the peak inspiratory pressure was adjusted with the Mapleson valve to approximate that which the patient had received when last on mechanical ventilation. The endotracheal tube was withdrawn on inspiration, the infant's nasopharynx and oropharynx immediately suctioned, and another three to five positive pressure breaths given with a bag and mask.

Experimental protocol. $\mathrm{Pes}, \mathrm{V}, \mathrm{V}_{\mathrm{t}}, \mathrm{RR}$, and $\mathrm{HR}$ were measured immediately postextubation $\left(\mathrm{t}_{0}\right)$ but prior to any treatment. Racemic epinephrine was then administered to infants in the treatment group and the warmed humidified gas to those in the control group. The study variables were recorded immediately following the treatment $\left(t_{1}\right)$ and at 10-min intervals for a total of $1 \mathrm{~h}\left(\mathrm{t}_{2}-\mathrm{t}_{6}\right)$. All infants also had continuous respiratory rate and heart rate monitoring (Hewlett-Packard, Cincinnati, OHI). Whenever possible, continuous Holter (Avionics, Irvine, CA) monitoring was done to screen for arrhythmias.

Infants in each group were placed in the head box (described below) following extubation. During each measurement period stable recordings of at least $20 \mathrm{~s}$ duration were obtained. Pes, $\stackrel{\circ}{\mathrm{V}}$, and $\mathrm{V}_{\mathrm{t}}$ measurements were obtained by averaging five to 10 representative values from each recording period. Respiratory rate was counted directly from the tracing and heart rate recorded from the infant's Hewlett-Packard monitor. Oxygen concentration $\left(\mathrm{FiO}_{2}\right)$ and box temperature $\left(33-35^{\circ} \mathrm{C}\right)$ were maintained at desired values between measurement periods by a heated nebulizer (Puritan-Bennett All Purpose, Puritan-Bennett Corporation, Kansas City, MO) and oxygen blender (Bird Corporation, Palm Springs, CA or Sechrist Industries, Anaheim, CA).

The racemic epinephrine aerosol was administered to infants 
in the treatment group via a mask and hand-held nebulizer (Puritan-Bennett Raindrop type) with the patient remaining in the head box.

Epinephrine dosage. A $0.2-\mathrm{mg} / \mathrm{kg}$ target dose of racemic epinephrine was chosen for patients receiving treatment. The choice of this dosage was somewhat empirical as few data are available regarding proper dosage, and no attempts to correct the dose for weight or $V_{t}$ have been made in any previous recommendations. We believed $0.2 \mathrm{mg} / \mathrm{kg}$ would certainly be high enough to demonstrate effects of the drug, without resulting in undue side effects. Calculations were made as follows.

1. $2.25 \%$ racemic epinephrine diluted $1: 4$ yields $4.5 \mathrm{mg}$ racemic epinephrine $/ \mathrm{ml}$.

2. $V_{t}$ was estimated at $7.0 \mathrm{ml} / \mathrm{kg}$.

3. Output of our nebulizer is $0.2 \mathrm{ml} / \mathrm{min}$ when driven by a gas source with a flow rate of 5 liter/min. (Puritan-Bennett Model 1058 Raindrop, particle size 3-5 $\mu$.)

4. Nebulizer therefore has an $0.9 \mathrm{mg} / \mathrm{min}$ racemic epinephrine output when the 1:4 racemic epinephrine dilution is nebulized 5 liter $/ \mathrm{min}$.

5. Aerosol deposition in the upper respiratory tract was estimated at $50 \%(6)$.

$$
\text { 6. } \frac{\mathrm{RR} / \mathrm{min} \times 7.0 \mathrm{ml} / \mathrm{kg} \times \mathrm{wt}(\mathrm{kg})}{5000 \mathrm{ml} / \mathrm{min}}=\text { inhaled fraction of total }
$$
flow

7. $(0.9 \mathrm{mg} / \mathrm{min}$ racemic epinephrine) $\times$ (inhaled fraction of total flow) $=\mathrm{mg}$ of racemic epinephrine inhaled $/ \mathrm{min}$.

8 . $\mathrm{Mg} / \mathrm{min}$ inhaled $\times 50 \%$ deposition $=\mathrm{mg}$ of racemic epinephrine deposited per min.

9. Duration (min) of administration of 1:4 racemic epinephrine aerosol required to provide the target dose of $0.2 \mathrm{mg} / \mathrm{kg}$ was thus estimated by:

$$
\frac{(0.2 \mathrm{mg} / \mathrm{kg}) \times \mathrm{wt}(\mathrm{kg})}{\mathrm{mg} / \mathrm{min} \text { racemic epinephrine deposited }}
$$

Esophageal pressure. Approximately $1 \mathrm{~h}$ prior to extubation feedings were discontinued and gastric contents were evacuated by syringe aspiration of the nasogastric tube. This tube was then removed and replaced by a neonatal gastric tube with esophageal balloon (National Catheter Corporation, Argyle, NY).

The catheter was inserted through the mouth into the esophagus. Reference marks on the catheter denote 5,10 , and $15 \mathrm{~cm}$ distances to the proximal end of the balloon. The measurements of Loew and Thibeault (7) were adapted to initially position the balloon in the esophagus at the level of the carina. The balloon was then inflated with $0.1 \mathrm{ml}$ of air, momentarily opened to atmosphere to allow the balloon to reach a minimal inflation volume, then closed. The catheter was then advanced in $1-\mathrm{cm}$ increments until regular negative deflections were obtained. The stomach was ausculated while $1.0 \mathrm{ml}$ of air was injected into the gastric channel to confirm catheter tip position in the stomach. The catheter was secured by tape to the patient's face.

The balloon channel was connected to a double 3-way stopcock with syringe, then connected in parallel to a water column and pressure transducer (Gould-Statham, no. 14363). The pressure transducer was connected to a three channel amplifier/ recorder (Gould 2400S). The water column was used to calibrate the pressure channel and "zeroed" by opening to atmosphere. Total change in Pes per breath was measured.

$\dot{V}$ and $V_{\mathrm{t}}$. Because attempts to obtain resting $\dot{V}$ with a mask and attached pneumotachograph often are not possible due to infants struggling and failing to lie quietly, and because recent studies have shown that data obtained by face mask may not

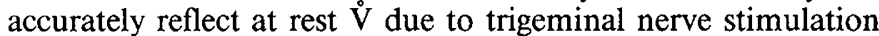
(8), we constructed a head box for this and similar studies, which allows the infant to lie untouched during measurement (Fig. 1). The box measures $20 \times 25 \mathrm{~cm}$ at the top, $20 \times 18 \mathrm{~cm}$ at the base, and is $20 \mathrm{~cm}$ high. It is constructed of 0.25 -inch thick clear acrylic. It has a rimmed circular head opening $13 \mathrm{~cm}$ in diameter, to which is fitted the collar section of an orthopedic surgeon's glove (Perry, Massillon, $\mathrm{OH}$ ). The infant is placed prone and the head is introduced through the opening while the collar is manually stretched down. Both the head and body are elevated with a 2 -inch thick pad to avoid pressure by the rim of the opening on the infant's neck. The collar is then gathered into a gentle yet slightly taut posture around the infant's neck and secured by curved forceps.

The airtight box cover can be quickly removed for access to the patient. $\mathrm{FiO}_{2}$ and air temperature are monitored continuously using sensors mounted in the wall of the box. The flow of warm, humidified gas can be reconnected to the box between each measuring period, or run continuously during measurement. A transmural adapter to connect the esophageal balloon catheter to a transducer is mounted in the box wall. A heated pneumotachograph (Dynasciences, Blue Bell, PA; Statham no. 15151 ) is connected to the airtight box and measures gas flow as the infant's spontaneous breathing displaces gas back and forth through the pneumotachograph. $\mathrm{V}_{\mathrm{t}}$ was obtained by electronic integration of the flow signal (Gould, no. 13-4615-70). All infants studied with the head box device settled into a quiet state within 1-2 min after being positioned in the box.

To validate the accuracy of the volume measurements made

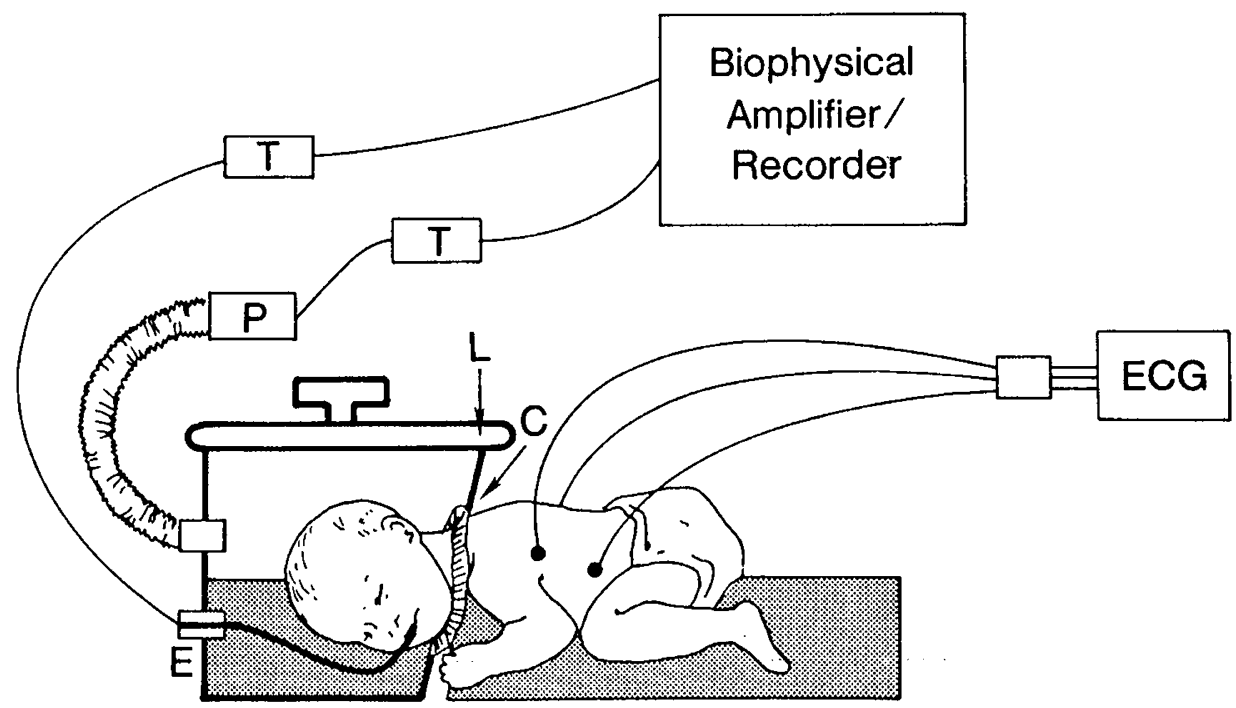

Fig. 1. Infant lying in head box. $T$, transducer; $P$, heated pneumotachograph; $E$, esophageal balloon catheter; $C$, gathered cuff at neck; $L$, removable lid; $E C G$, electrocardiograph. 


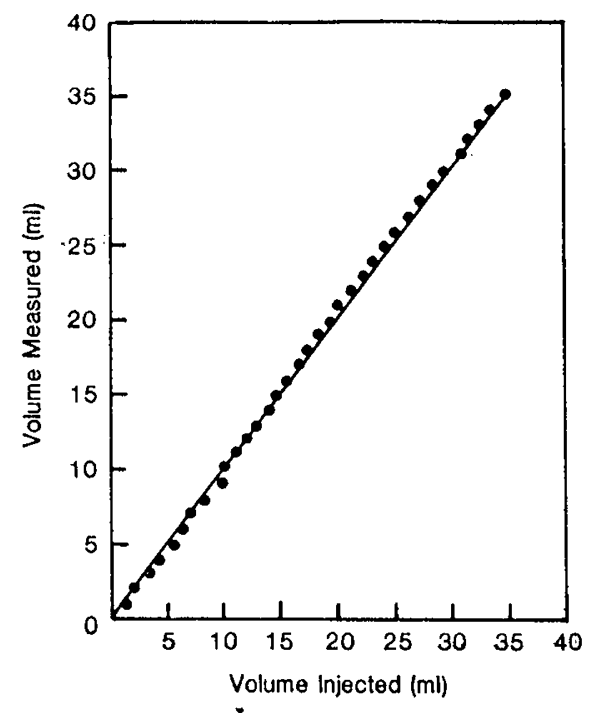

Fig. 2. Validation of pneumotachograph volume measurements made with head box. Each point represents the average of 10 injections.

with the head box the Gould-Statham flow transducer was calibrated with standardized flowmeters. The volume integrater channel was calibrated with a 35-ml syringe for a full scale reading of 0 to $35 \mathrm{ml}$. Subsequently, the head box was then sealed with a rubber diaphragm and a $35-\mathrm{ml}$ syringe was attached. The syringe was repeatedly injected into the box 10 times at each marked volume from 1 to $35 \mathrm{ml}$ (Fig. 2).

Following recalibration flow independence of the volume measurements was also validated. A $15-\mathrm{ml}$ syringe was injected into the head box 16 times at varying $\mathrm{V}$ from 0.7 to 3.5 liter/ min. Average volume returned was $15.1 \mathrm{ml}$ with a range of 14.8 to $15.6 \mathrm{ml}$.

Resistance. Using the recorded tracings of ${ }^{\circ}, V_{t}$, and Pes, $R_{L}$ was calculated as described by Cook et al. (9), for $t_{0}, t_{3}$, and $t_{6}$.

Statistical analysis. Analyses were performed using the SAS and an IBM 3083 computer. Spearman and Pearson correlation coefficients were used to examine relationships between variables. ANOVA was performed, involving covariance adjustment for covariables as necessary, and testing time, sex, treatment, and their interactions. When appropriate Duncan's multiple range test was used to help identify subgroups.

\section{RESULTS}

The two groups were initially examined for differences among the covariables presented in Table 1, using a simple ANOVA model with study group, sex, and group by sex interaction. There was a significant group effect for extubation weight $(p=0.02)$. Infants in the treatment group had, by chance, significantly smaller extubation weights than those in the control group (1.43 versus $1.81 \mathrm{~kg}$ ). Since gestational age, birth weight, and extubation weight are highly correlated, it is not surprising that group effects for gestational age and birth weight bordered on significance ( $p=0.052$ and 0.054 , respectively). Therefore, it was necessary in subsequent analyses to make adjustment for these covariables. As some blood gases were obtained by capillary stick and others by arterial sampling, $\mathrm{PO}_{2}$ values were not analyzed.

The correlation matrix of all study variables and covariables was examined to determine statistically significant $(p=0.05)$ relationships between pairs of variables. There were no significant correlations between any study variable and any covariable.

In the analysis of the study variables, ANOVA models were used that included the initial value of the variable $\left(t_{0}\right)$, treatment status, time, and sex main effects, and all possible interactions of treatment, time, and sex. Surprisingly, sex effects and sex by treatment interactions were common, so analyses were repeated sex specifically. There were no significant treatment by time interaction effects nor were there time effects with the single exception of a slight time effect for $\Delta \mathrm{HR}$ in girls $(p=0.02)$.

The absence of time effects for virtually all variables allowed us to simplify the analysis and presentation of results by determining the mean value of each variable over all posttreatment times $\left(t_{1}\right.$ through $\left.t_{6}\right)$ and to calculate the response for each variable as the difference between the pretreatment level at $t_{0}$ and the mean of the posttreatment levels. Table 2 presents descriptive statistics for pretreatment values of variables and their corresponding mean response.

A paired $t$ test was used to test the null hypothesis that the mean response (posttreatment minus pretreatment) was not significantly different from zero. Only three of the 20 response means presented in Table 2 are significantly different from zero and they show no pattern consistent with an overall treatment effect. The patterns of the mean responses given in Table 2 are consistent with the results obtained when the responses for each of the time periods $\left(t_{1}\right.$ through $\left.t_{6}\right)$ were considered separately. Thus, both the ANOVA results and the paired $t$ test indicate that there were no significant treatment effects in $\mathrm{V}$, Pes, or $\mathrm{Vt} / \mathrm{kg}$. Small and sometimes inconsistent treatment effects occurred for $\mathrm{RR}$ and heart $\mathrm{HR}$, the latter more pronounced in females.

$R_{L}$ measurements showed a significant increase in $R_{L}$ for the control group at $t_{6}$ (Table 3 ). Sex-specific evaluation showed this effect to occur only in males. Correction of values for extubation weight did not alter this result. No other covariables were found to influence $R_{L}$.

As Holter monitoring was only done in 16 of the infants due to technical difficulties, we cannot state whether arrhythmias may be more common after the aerosol treatment. Of the 16 monitored infants, two in the treatment group (one, bradycardia; one, atrioventricular dissociation) and four in the control group (two, bradycardia; two, tachycardia) had various abnormalities noted on the Holter reports. All abnormalities were of brief duration. None of the infants experienced apnea.

One infant was a study failure; this child had been intubated for 43 days and developed respiratory distress and stridor immediately postextubation. The study was discontinued on this infant-he had been in the control group-and racemic epinephrine was given empirically by his physician and continued every $4 \mathrm{~h}$ for 3 days, when his distress was considerably abated.

\section{DISCUSSION}

Nebulized racemic epinephrine has been used in the treatment of croup in children and has been shown to be efficacious in

Table 1. Descriptive statistics for covariables in treatment and control groups (mean $\pm S D$ )

\begin{tabular}{lcc}
\hline & Treatment & Control \\
\hline Males & $n=10$ & $n=14$ \\
Females & $n=12$ & $n=8$ \\
GA* $^{*}$ wk) & $30.9 \pm 2.9$ & $32.7 \pm 3.1$ \\
Age int (days) & $1.1 \pm 0.3$ & $1.2 \pm 0.5$ \\
Age ext (days) & $19.0 \pm 17.0$ & $17.5 \pm 15.4$ \\
BW (kg) & $1.44 \pm 0.44$ & $1.81 \pm 0.75$ \\
Ext wt $\dagger$ (kg) & $1.43 \pm 0.36$ & $1.81 \pm 0.69$ \\
Apgar 1 & $4.7 \pm 2.5$ & $4.5 \pm 2.4$ \\
Apgar 5 & $6.1 \pm 2.0$ & $6.7 \pm 2.0$ \\
Reint $(n)$ & $1.8 \pm 2.0$ & $2.2 \pm 2.2$ \\
Length int (days) & $17.9 \pm 17.0$ & $16.2 \pm 15.6$ \\
pH $_{\mathrm{B}}$ & $7.37 \pm 0.05$ & $7.38 \pm 0.05$ \\
$\mathrm{PCO}_{2 \mathrm{~B}}$ & $40.3 \pm 5.4$ & $41.8 \pm 7.9$ \\
pH $_{\mathrm{A}}$ & $7.36 \pm 0.04$ & $7.35 \pm 0.07$ \\
$\mathrm{PCO}_{2 \mathrm{~A}}$ & $41.2 \pm 5.2$ & $43.1 \pm 7.0$ \\
\hline
\end{tabular}

* GA, gestational age; int, intubation; ext, extubation; BW, birth wt; reint, reintubations; B, before study; A, after study.

$\dagger p<0.05$. 
Table 2. Means and SD for initial values (subscript 0) and mean responses * ( $\Delta$ ) of study variables by sex and treatment group

\begin{tabular}{|c|c|c|c|c|c|c|c|c|}
\hline \multirow[b]{3}{*}{ Variable } & \multicolumn{4}{|c|}{ Males } & \multicolumn{4}{|c|}{ Females } \\
\hline & \multicolumn{2}{|c|}{$\begin{array}{l}\text { Treatment } \\
(n=10)\end{array}$} & \multicolumn{2}{|c|}{$\begin{array}{l}\text { Control } \\
(n=14)\end{array}$} & \multicolumn{2}{|c|}{$\begin{array}{l}\text { Treatment } \\
(n=12)\end{array}$} & \multicolumn{2}{|c|}{$\begin{array}{l}\text { Control } \\
(n=8)\end{array}$} \\
\hline & Mean & $\mathrm{SD}$ & Mean & $\mathrm{SD}$ & Mean & SD & Mean & SD \\
\hline$\dot{\mathrm{V}}_{0}$ & 1.12 & 0.45 & 1.45 & 0.69 & 1.09 & 0.65 & 1.09 & 0.61 \\
\hline$\Delta \dot{\mathrm{V}}$ & 0.07 & 0.36 & -0.17 & 0.50 & -0.16 & 0.62 & -0.20 & 0.39 \\
\hline $\mathrm{Pes}_{0}\left(\mathrm{~cm} \mathrm{H} \mathrm{H}_{2} \mathrm{O}\right)$ & 1.63 & 0.73 & 2.84 & 1.60 & 2.23 & 1.29 & 1.89 & 1.10 \\
\hline$\Delta$ Pes & 0.28 & 0.90 & 0.70 & 1.37 & -0.21 & 0.88 & -0.01 & 0.92 \\
\hline $\mathrm{Vt} / \mathrm{kg}_{0}(\mathrm{ml})$ & 5.42 & 2.68 & 6.67 & 2.87 & 6.22 & 5.38 & 4.49 & 2.24 \\
\hline$\Delta \mathrm{Vt} / \mathrm{kg}$ & 0.42 & 2.54 & 0.09 & 2.68 & -0.99 & 4.75 & -0.21 & 1.42 \\
\hline $\mathrm{HR}_{0}$ (beats/min) & 158.4 & 10.3 & 149.4 & 20.6 & 149.5 & 14.4 & 160.1 & 14.5 \\
\hline$\Delta \mathrm{HR}$ & -2.2 & 9.2 & -6.6 & 16.4 & $8.7 \dagger$ & 11.2 & $-13.3 \ddagger$ & 9.8 \\
\hline $\mathrm{RR}_{0}(\mathrm{resp} / \mathrm{min})$ & 82.8 & 20.7 & 81.4 & 25.9 & 77.0 & 30.2 & 75.0 & 16.7 \\
\hline$\Delta R R$ & -4.2 & 21.6 & $-1.09 \dagger$ & 15.1 & -8.9 & 18.7 & 2.0 & 14.7 \\
\hline
\end{tabular}

* Mean responses are calculated as the average response at each of the six times of measurement. A positive value indicates an increase and a negative value a decrease relative to the initial $\left(\mathrm{t}_{\mathrm{o}}\right)$ value.

For testing Ho: response mean $=0, \dagger 0.01<p \leq 0.05 ; \ddagger p \leq 0.01$.

Table 3. $\mathrm{R}_{L}\left(\mathrm{~cm} \mathrm{H}_{2} \mathrm{O} /\right.$ liter/min)

\begin{tabular}{|c|c|c|c|c|c|c|c|c|}
\hline \multirow[b]{3}{*}{ Time } & \multicolumn{4}{|c|}{ Males } & \multicolumn{4}{|c|}{ Females } \\
\hline & \multicolumn{2}{|c|}{$\begin{array}{l}\text { Treatment } \\
(n=10)\end{array}$} & \multicolumn{2}{|c|}{$\begin{array}{l}\text { Control } \\
(n=14)\end{array}$} & \multicolumn{2}{|c|}{$\begin{array}{l}\text { Treatment } \\
(n=12)\end{array}$} & \multicolumn{2}{|c|}{$\begin{array}{l}\text { Control } \\
(n=8)\end{array}$} \\
\hline & Mean & SD & Mean & $\mathrm{SD}$ & Mean & $\mathrm{SD}$ & Mean & SD \\
\hline 0 & 41.8 & 36.8 & 38.9 & 24.8 & $46.2^{*}$ & 31.9 & 35.5 & 28.0 \\
\hline 30 & 63.6 & 52.1 & 49.5 & 30.6 & $64.2 \dagger$ & 34.1 & 46.2 & 22.5 \\
\hline 60 & 47.3 & 31.3 & $65.4 \ddagger \S$ & 38.0 & 45.2 & 22.4 & 49.6 & 33.1 \\
\hline
\end{tabular}

$*_{n}=11$

$\dagger n=10$, variation in $n$ indicates inability to calculate accurate $\mathbf{R}_{\mathrm{L}}$ from some tracings.

$\ddagger n=13$.

$\S 0.01<p<0.05$.

several studies (10-12). Apparently, extrapolation from these studies has led to recommendations for its use in the newborn, although no studies of which we are aware have ever proven its efficacy in this age group.

Laryngeal damage from intubation does occur in the newborn (13) and has been shown to be related to length of intubation and number of reintubations $(5,14)$. Thus, only infants intubated for more than 3 days were included in the present study. As gestational age has been shown not to be a factor in prediction of laryngeal injury, the significant difference in extubation weight between the treatment and control groups and the nearly significant differences in gestational age and birth weight are not likely to be of importance.

We were unable to identify any trend toward cardiac abnormalities resulting from the racemic epinephrine other than a change in heart rate, which was more pronounced in females. Females in the treatment group had a significant increase in HR while the control group showed a significant decrease. In males, both groups showed negative responses but the treatment group had a smaller negative response than the control group. The tendency for an increase in HR is consistent with at least some systemic absorption of catecholamine. Measurement of serum catecholamine levels would be useful in future studies. If Holter monitoring had been possible on all infants a clearer idea of possible cardiac effects might have been obtained. The demonstrated increase in HR in females and reports of cardiac arrhythmias and apnea during its use $(2,13)$ make cardiorespiratory monitoring mandatory during administration of racemic epinephrine.

We believe the head box we developed is superior to the more commonly used mask technique for measuring air flow. Infants quieted almost immediately and were undisturbed throughout the entire study period. Leaks around the neck seal were immediately detected, as any leak entirely prevented measurements from being transmitted and recorded. Measurements obtained in this manner may be more indicative of true resting values than measurements obtained by face mask, due to the lack of trigeminal stimulation afforded by the head box. Although it is unlikely, the neck seal may affect venous return. Studies are underway to evaluate these aspects of the head box.

The investigators were not blinded as to study group since no "soft" measurements, such as degree of stridor, were being made. Any bias among investigators and our nursery staff was unquestionably towards effectiveness of racemic epinephrine treatments; therefore, it is unlikely to have influenced the study results.

The significant sex by group interactions were unexpected and may not be biologically important as no definite trends were demonstrated. Most important was the lack of demonstrated treatment effect, when compared to $t_{0}$, for $\Delta \dot{V}, \Delta P e s$, or $\Delta V_{t} / k g$. Although $R_{L}$ increased in control group males at $t_{6}$, values are still within normal limits reported for $R_{L}$ in preterm infants (15). Thus, no physiological significance of this finding is likely. All other values of $R_{L}$ are also within normal range. Although the respiratory system resistance as measured in this study is not specifically upper airway resistance, changes in upper airway resistance would be reflected in these values and constitute a major part of such changes. In the infants studied sudden changes in lower airway resistance would be unlikely.

In our experience infants with laryngeal edema severe enough to cause respiratory distress become symptomatic immediately following extubation. With the exception of the one study failure, none of our infants demonstrated this finding, nor did distress develop within $24 \mathrm{hr}$ in any baby. In the study failure infant, the fact that improvement occurred over 3 days suggests that time, as much as aerosolized epinephrine treatment, may have been important in improving this infant's clinical status. It is possible that none of the 45 infants had any laryngeal edema; if so, this would also argue favorably for abandoning the routine use of this drug postextubation. The degree of laryngeal edema in our patients would have been difficult, if not impossible, to quantify prior to the study. As the average length of intubation was about 17 days in both treatment and control groups with some infants much exceeding this, total lack of edema seems unlikely. It is more likely that edema, if present, was mild and thus expected changes did not occur in the treatment group. This would indicate that, even after prolonged intuhation, most infants do not require prophylactic therapy with catecholamines, or with other agents, such as steroids, administered to reduce or resolve laryngeal edema. Such agents may possibly be effective in cases 
of respiratory distress due to documented laryngeal edema, but no studies are available to demonstrate the effectiveness of these agents in such cases.

A maturational difference in response to racemic epinephrine must be considered, as those in the treatment group were somewhat smaller and less mature than those in the control group. If anything, however, the less mature infant may even be more responsive to catecholamines. Catecholamines are present in the fetus very early, and HR may respond to epinephrine as early as $8 \mathrm{wk}$ of gestation (16). A relative deficiency of monoamine oxidase in preterm infants, leading to increased urinary catecholamines, has been reported (17). One might postulate that the more immature child might thus be even more sensitive to the effects of catecholamines.

In conclusion, we have demonstrated in a prospective, randomized study of 44 infants that racemic epinephrine aerosol is not indicated as a routine in the infant postextubation. The drug may be of value in cases of obvious stridor, although one must remember that stridor may also be due to tracheal stenosis or other abnormalities which will not respond to medication.

\section{REFERENCES}

1. Caldwell CC, Levkoff AH, Purohit DM 1977 Paroxysmal supraventricular tachycardia in a neonate. Clin Pediatr 16:579-580

2. Marshall TA, Pai S 1984 The effects of racemic epinephrine aerosol therapy after prolonged intubation in preterm infants. Respir Care 29:138-143

3. Avery GB 1981 Appendix H, Drugs. In: Avery GB (ed) Neonatology. JB Lippincott Co, Philadelphia, pp 1216-1226
4. Nugent J, Hanks H, Goldsmith JP 1981 Pulmonary Care. In: Goldsmith JP, Karotkin EH (eds) Assisted Ventilation of the Neonate. WB Saunders Co, Philadelphia, pp 67-80

5. Fan LL, Flynn JW, Pathak DR 1983 Risk factors predicting laryngeal injury in intubated neonates. Crit Care Med 11:431-433

6. Brain JD, Valberg PA 1979 Deposition of aerosol in the respiratory tract. Am Rev Respir Dis 120:1325-1373

7. Loew A, Thibeault DW 1974 A new and safe method to control the depth of endotracheal intubation in neonates. Pediatrics 54:506-507

8. Fleming PJ, Levine MR, Goncalves A 1982 Changes in respiratory pattern resulting from the use of a face mask to record respiration in newborn infants. Pediatr Res 16:1031-1034

9. Cook CD, Sutherland JM, Segal S, Cherry RB, Mead J, McIlroy MC, Smith CA 1957 Studies of respiratory physiology in the newborn infant. III Measurements of the mechanics of respiration. J Clin Invest 36:440-448

10. Taussig LM, Castro O, Beauding PH, Fox WW, Bureau M 1975 Treatment of laryngotracheobronchitis (croup). Am J Dis Child 129:790-793

11. Singer OP, Wilson WJ 1976 Laryngotracheobronchitis: 2 years' experience with racemic epinephrine. Can Med Assoc J 115:132-134

12. Fogel JM, Berg IJ, Gerber MA, Sherter CB 1982 Racemic epinephrine in the treatment of croup; nebulization alone versus nebulization with intermittent positive pressure breathing. Pediatrics 101:1028-1031

13. Hengerer AS, Strome M, Jaffe BJ 1975 Injuries to the neonatal larynx from long-term endotracheal tube intubation and suggested tube modification for prevention. Ann Otol 84:764-770

14. Joshi VV, Mandavia SG, Stern L, Wigglesworth FW 1972 Acute lesions induced by endotracheal intubation. Am J Dis Child 124:646-649

15. Auld PAM 1975 Pulmonary Physiology of the Newborn Infant. In: Scarpelli EM (ed) Pulmonary Physiology of the Fetus, Newborn, and Child. Lea and Febiger, Philadelphia, pp 140-165

16. Loggie JMH, VanMaanen IF 1972 The autonomic nervous system and some aspects of the use of autonomic drugs in children. J Pediatr 81:205-216

17. Brunjes S, Castner E, Hodgman J 1964 Catecholamine metabolism in newborn infants. Clin Res 12:88 